\title{
Erratum zu: Real Driving Emissions (RDE)
}

\section{Helmut Tschöke}

Der ursprüngliche Buchtitel „Real Drive Emissions (RDE)“ wurde geändert in „Real Driving Emissions (RDE)“.

Die Korrektur wurde auf dem Umschlag vorgenommen sowie auf den Seiten III, VII, 95 und in der Quellenangabe am Fuß der Kapitelanfangsseiten.

Die korrigierte Version des Buches ist verfügbar unter https://doi.org/10.1007/978-3-658-21079-3.

H. Tschöke ( $\square)$

Institut für Mobile Systeme, Otto-von-Guericke-Universität

Magdeburg, Deutschland

(C) Springer Fachmedien Wiesbaden GmbH, ein Teil von Springer Nature 2019

E1

H. Tschöke (Hrsg.), Real Driving Emissions (RDE), ATZ/MTZ-Fachbuch, https://doi.org/10.1007/978-3-658-21079-3_12 